\title{
Clinical perspective on the impact of coronavirus (COVID-19) pandemic on individuals with glucose -6- phosphate dehydrogenase deficiency (G6PD)
}

\author{
Abdelrahim A Hunaiti* \\ Department of Clinical Laboratory Sciences, School of Science University of Jordan, Jordan
}

Glucose-6-phosphate dehydrogenase (G6PD) is an enzyme that catalyzes the initial and the rate-limiting reaction step in the pentose phosphate pathway (HMP) which converts NADP into NADPH. $\mathrm{NADPH}$ is required for the generation of reduced glutathione an important antioxidant used to protects red blood cells from oxidative damage.Glucose-6-phosphate dehydrogenase (G6PD) deficiency is the most common enzymopathy worldwide, affecting an estimated 400 million people and exists in concentrated regions in Africa, the Middle East, and Southeast Asia, and about one in 10 African-American males are affected in the United States [1-3]. G6PD-deficient patients may develop acute hemolytic anemia after exposure to oxidative stress because the HMP shunt is their only source of NADPH. Oxidative stress constitutes a failure of anti-oxidation defence systems to keep reactive oxygen and nitrogen species under control due to decrease of reduced glutathione synthesis in G6PD-deficient patients [4]. Hemolytic anemia may be life-threatening in some individuals due to three main triggers for hemolytic anemia in G6PD-deficient patients these are bacterial or viral infections, certain foods, and certain drugs [5]. These factors can increase the levels of reactive oxygen species, causing red blood cells to be destroyed faster than the body can replace them. Investigators found that G6PD-deficient cells were more susceptible to infection and death by human coronavirus, HCoV229E, a common pathogen for respiratory tract infection [6].In previous study we noticed a concurrent decrease in the concentration of reduced glutathione when the G6PD activity decreased [7]. Furthermore, we presented evidence that maintaining glutathione levels may help in easing the symptoms of certain diseases and supplementation of bilingual glutathione as a therapeutic strategy [8]. Since the onset of the COVID-19 pandemic and in light of the notion that some people become severely ill while others are asymptomatic, researchers started to believe that people who have a G6PD deficiency may be significantly affected by COVID-19 pandemic like the human coronavirus, HCoV229E and raised the question: Is there any scientific evidences to support a correlation/ association between G6PD deficiency and COVID-19 infection, susceptibility, severity or mortality [9]. Recent retrospective studies strongly suggesting that G6PD-deficient COVID-19 patients may suffer highest chloroquine induced toxicity a drug along with hydroxychloroquine are commonly prescribed widely used worldwide in the treatment of COVID-19 pandemic [10,11]. Moreover, a brief overview of the protective action of GSH against the exacerbated inflammation triggered by COVID-19 upon ACE/ACE2 imbalance was reported [12]. Additional evidence continued to suggest G6PD deficiency may not only play a role in COVID-19 susceptibility, but also severity of infection, therefore in order to answer this question, it would be necessary to test some COVID-19 patients to determine whether they have G6PD deficiency and determine if any correlation is established between G6PD deficiency and susceptibility to , severity and mortality rate of COVID-19 pandemic especially many COVID-19 patients may not be aware that they have a G6PD deficiency disorder. In the past few years, there have been substantial advances in testing for G6PD deficiency and rapid in-laboratory testing is now available which make it easy for health caregivers to monitor COVID-19 patients with G6PD deficiency and to take some aggressive measures to circumvent further decline in their health conditions. We recommend G6PD testing before using certain drugs such chloroquine, hydroxychloroquine, antibiotics and medications used to treat malaria. Furthermore, reducing the oxidative stress by increasing the level of reduced glutathione using Sublingual reduced glutathione supplementation is probably the best approach to protect the most vulnerable subjects from COVID-19.

\section{References}

1. Cappellini MD, Fiorelli G (2008) Glucose-6-phosphate dehydrogenase deficiency. Lancet 371:64-74. [Crossref]

2. Nkhoma ET, Poole C, Vannappagari V, Hall SA, Beutler E (2009) The global prevalence of glucose-6-phosphate dehydrogenase deficiency: a systematic review and meta-analysis. Blood Cells Mol Dis 42: 267-78. [Crossref]

3. Talafih K, Hunaiti A, Gharaibeh N, Gharaibeh M, Jaradat S (1996) The Prevalence of Hemoglobin S and Glucose-6-Phosphate Dehydrogenase Deficiency in Jordanian Newborn. J Obstet Gynaecol Res 22: 41 7-420. [Crossref]

4. Ho HY, Cheng ML, Chiu DT (2007) Glucose-6-phosphate dehydrogenase-from oxidative stress to cellular functions and degenerative disease. Redox Rep 12: 109-118. [Crossref]

5. Bubp J, Jen M, Matuszewski K (2015) Caring for Glucose-6-Phosphate Dehydrogenase (G6PD)-Deficient Patients: Implications for Pharmacy. P T 40: 572-574. [Crossref]

6. Wu YH, Tseng CP, Cheng ML, Ho HY, Shih SR, et al. (2008) Glucose-6-phosphate dehydrogenase deficiency enhances human coronavirus 229E infection. J Infect Dis 197: 812-816. [Crossref]

7. Hunaiti A, Al-shareef M (1997) Interplay between Glutathione-S-Transferase and Glucose6Phosphate Dehydrogenase in Neonatal Cord Blood. Biol Neonate 72: 273 278. [Crossref]

8. Hunaiti A (2020) The Therapeutic Potential of Glutathione Supplement: A Review of Clinical Trials. Eur J Med Health Sci 2.

*Correspondence to: Abdelrahim A Hunaiti, Department of Clinical Laboratory Sciences, School of Science University of Jordan, Amman, Jordan, E-mail: hunaiti2001@gmail.com

Received: February 19, 2020; Accepted: February 28, 2020; Published: March 06, 2020 
Hunaiti AA (2020) Clinical perspective on the impact of coronavirus (COVID-19) pandemic on individuals with glucose -6- phosphate dehydrogenase deficiency (G6PD)

9. Dan J. Vick D J (2020) Does G6PD Deficiency Relate to COVID-19 Infection. MedPage Today article.

10. Taccone FS, Gorham J, Vincent JL (2020) Hydroxychloroquine in the management of critically ill patients with COVID-19: the need for an evidence base. Lancet Respir Med 8: 539-541. [Crossref]
11. Dar SA, Wahid M, Haque S, Almalki SS, Akhter N (2020) Hydroxychloroquine (HCQ) use in G6PD deficient COVID-19 patients and the risk of Acute Hemeolytic Anaemia (AHA). Eur Rev Med Pharmacol Sci 24: 7923-7924. [Crossref]

12. Silvagno F, Vernone A, Pescarmona GP (2020) The Role of Glutathione in Protecting against the Severe Inflammatory Response Triggered by COVID-19. Antioxidants 9 624. [Crossref]

Copyright: (C2020 Hunaiti AA. This is an open-access article distributed under the terms of the Creative Commons Attribution License, which permits unrestricted use, distribution, and reproduction in any medium, provided the original author and source are credited. 